\title{
Institutional Adoption of a Learning Management System in Higher Education: A Case Study of the Corvinus University in Budapest
}

\author{
Péter BALKÁNYI, ${ }^{1}$ Zsolt ORBÁN²
}

\begin{abstract}
The development of the Moodle e-learning system started in 2002. Since it is an open source platform with a prominently rich functionality, the system has been introduced in more than 100,000 organisations ${ }^{3}$ worldwide in the last decade, including numerous Hungarian higher education institutions (Szent István University, Óbuda University, University of Pannonia) and many organisations in the public administration. We have been operating with one of the largest user (12,000 visitors daily) and course (more than 1,000 active courses per semester) numbers in Hungary, a Moodle based system since 2007 at the Corvinus University of Budapest (CUB) with a high level of user satisfaction.

We managed a major, overall system improvement project at CUB in 2016. The development included a version upgrade to the newest Moodle 3, a full redesign, introduction of several new functions regarding the professors' needs and core improvement on the system's stability and security among others with a comprehensive load-impact test.

In this paper, we discuss the success factors and pitfalls of the whole renewal process. We will further focus on analysing the group discussions with the major stakeholders and evaluate the comprehensive load-impact test. At the end of our paper, we will examine the state of the Moodle e-learning system at the National University of Public Service and we will propose elements of an improvement project relying on our recent experience at another university.
\end{abstract}

Keywords: e-learning, Moodle, learning management system, Corvinus University of Budapest, National University of Public Service, IT project management

\section{Introduction}

Following the implementation of the central Moodle e-learning system at the Corvinus University of Budapest (CUB) in 2009, no significant organisational or information

Assistant Research Fellow, Corvinus University of Budapest, Teacher Training and Digital Learning Center; e-mail: peter.balkanyi@uni-corvinus.hu

2 Assistant Research Fellow, Corvinus University of Budapest, Teacher Training and Digital Learning Center; e-mail: zsolt.orban@uni-corvinus.hu

3 Source: https://moodle.net/stats/ (Downloaded: 10.09.2018). 
technological advances were made for many a year. This lack of improvement was mainly due to the fact that before 2015, the CUB had no dedicated unit to supervise the e-learning services. In 2015, the former Teacher Training Centre and the e-Learning Teaching and Service Centre (that previously had informally operated the university's e-learning system within the framework of the Department of Infocommunications, a member of the Institute of Information Technology at CUB) merged and thus the Teacher Training and Digital Learning Centre (TTDLC) was created. The Centre received a priority status both technologically and methodologically and was tasked with the organisation of digital learning and teaching. Also, it was in these years that the university laid the foundations for the organisational, technological, methodological and financial developments which today provide a secure operational framework for one of the most significant e-learning systems in Hungary. As one of the greatest achievements of the new organisational unit, the new, redesigned and technologically upgraded system was launched in pilot form in the autumn of 2016 and went fully operational in the spring of 2017, proudly servicing almost all the students of the university.

In the present article, we propose to present the findings of the scientific research that complement the numerous organisational, methodological and technological transformation processes and to investigate the entire development process with scientific rigour with the methodology of case study (CS). Through the investigation and the analysis, we aim to formulate general good practices and advice that could be utilised as parts of a guiding vision by other large organisations when developing their own Moodle-based e-learning systems. As Veronika Nagy Takács and Colonel Professor László Kovács put it in their article entitled Partial Experience of Specific Training for Leaders of Information Security, [1] students may have a variety of educational background and the trainings also shape the students' attitude, therefore it is recommended to provide them with customised knowledge. These circumstances and goals can be formed and attained through trainings supported by a carefully designed e-learning toolkit.

To these ends, we shall first give a brief overview of the developed e-learning system then provide a comprehensive analysis of the key stakeholders and explore the history and functions of the TTDLC, as it is the unit that made the development possible in the first place. We have pointed out in an earlier study [2] that e-learning system development is not to be regarded as a mere IT development, a process only determined by technological details; the suitable environment and the in-depth knowledge and analysis of the organisational background also play a crucial part in the development process. The scientific acceptance of this approach is illustrated by a 2017 study written by Kovács, Nemeslaki, Orbók and Szabó bearing the title Structuration Theory and Strategic Alignment in Information Security Management: Introduction of a Comprehensive Research Approach and Program [3] which highlights that "[a]lignment is about the process to ensure that the organizational strategies adapt harmoniously both horizontally and vertically”. During the system development at the CUB, we were fortunate to be able to follow how this theory is put into practice. Working with Moodle means adopt open source IT and educational technology and therefore we had to face some typical IT adaptation challenges, like always advancing technologies, fashion trends etc. It is also clear that the development of Moodle by itself will not be a long-time success without improvements in the fields of "organizational structure, infrastructure, processes and mindsets". [4] Hameed, Counsel and Swift summarised that IT adoption is 
based on innovational, organisational, environmental and individual characteristics and user acceptance models. Concerning the organisational characteristics, IT adaptation seeks organisational readiness, top management support, product champions, infrastructure and cultural attributes. The research about environmental characteristics shows that external environments are also crucial factors in adopting a new technology regarding competitive pressure, government support, etc. About the individual characteristic: innovativeness, attitude, IT knowledge are important characteristics of a top manager. [5]

Considering all the above, in this paper, after the introduction of the organisational environment, we analyse the following three dimensions of the system implemented as a result of the development process:

- stability;

- functionality;

- design.

The present article aims to elaborate on the first dimension, as we are convinced that without establishing stability, that is, an adequate IT security framework and a service environment capable of meeting the demand, it is pointless to speak about the functionality or the design of the system.

Following the development process, we sought to investigate the result from a variety of aspects. Considering that the development is a personal and a highly practice-oriented process, we essentially performed research and development adopting a cooperative approach, actively and continuously participating in the analysis of theoretical and practical research issues. [6] This approach prompted us to investigate the organisation through a stakeholder interest analysis, to evaluate the design modification with the help of a survey and to analyse stability via load testing. In the following, we will present these research phases, draw our conclusions and recommend possible directions for development.

\section{About the Research Methodology}

This paper is based on our case study (CS) at Corvinus University of Budapest. The CS research is based on observation and analysis of the development of the learning management system (LMS) and we were looking for the answers for the "how?” and "why?" questions. A CS research do not aim to find solutions, it aims to systematically analyse a practical question. [7] [8] [9] CS is a "necessary and sufficient method”. [10] We took four viewpoints into consideration:

1. we were looking for context and the object of the observation (the learning management system) at the same time;

2. our research was an empirical study, since as researchers, we were part of the development;

3. we were also the interpreters of the observations;

4. we were emphatic about the development regarding our involvement. [11] [12] 
P. BALKÁNYI, Zs. ORBÁN: Institutional Adoption of a Learning Management System...

The advantage of a CS is the ability to use a wide perspective, to analyse whether in depth and coherence can be found. [13] The CS do not have a well-defined procedure, so it is hard to build the research on it. [12]

\section{A Brief Introduction of the e-Learning System}

The central e-learning system of the CUB is based on Moodle, an open-source learning management system (LMS), originally developed for higher educational purposes. Moodle is written in PHP and distributed under the GNU GLP license. The acronym Moodle stands for Modular Object-Oriented Dynamic Learning Environment. At present, Moodle is servicing over 100,000 entities all over the world in more than 228 countries. [14]

The LMS manages the various university courses where learning aids (PPT lectures, guiding manuals in PDF format, etc.) can be uploaded, or complex e-learning content (interactive files, videos, etc.) can be played. The platform supports automated assessment at the end of the courses by selecting random questions for the examinees, measuring the time they have to complete the exercises, and so on. Moodle also automatically corrects tests and, depending on the settings, informs the professor and/or the student of the result. The platform also generates detailed reports covering all student activities (time spent studying, progress, passed/failed exams, etc.) for the professors.

Beyond the above, Moodle also has all the major content management and e-learning functions that are important in the context of higher education. It, for instance, can be integrated with other IT systems. Furthermore, this innovative system has the capacity to stimulate development in a number of fields, such as the area of stationary augmented reality e-learning applications. [15] Moodle also satisfies a wide variety of educational needs with the following features and functionalities: file sharing, playing e-learning content (SCORM), built-in learning content editor, tests, examinations, hand-in assignments, group work, group management, performance assessment, feedback, modular course structure, a wide variety of communication tools (forum, chat, internal message system), blogs, glossaries, wiki module and gamification elements.

\section{The Organisational Background and the Stakeholders}

Before 2015, two organisational units attended affairs in connection with digital support provided for teachers and students of the CUB. One of these, the Teacher Training Centre mainly supported new teachers and those participating in professional development programs, while the enthusiastic and dedicated employees of the Centre also sought to shape their colleagues' attitude and provide methodological support in respect of digital education. The other such organisational units started out as a grassroots initiative, such as the e-Learning Teaching and Service Centre (eLTSC), and it, with the support of the IT Service Centre (ISC), created the e-learning system servicing the entire University.

The Teacher Training and Digital Learning Centre (TTDLC) was born out of the marriage of these two organisations and approaches (methodology and technology) in February 2015. The new Centre "on the one hand is the organizational unit responsible 
for the training of new teachers and for the coordination of the work of all institutes and departments participating in teacher training ensuring the cooperation thereof. On the other hand, the Centre is expected to operate as a central hub, and to provide e-learning-related methodological and technological services to the University”. [20] Besides, the organisation:

- provides support to university students in connection with learning content development and helps them understand how to use the system;

- oversees the IT aspects of the development process;

- acts as Moodle platform supervisor and offers customer services.

We firmly believe that the foundation of the TTDLC was instrumental in improving the system and in promoting e-learning while providing services of higher standards at CUB. Without the proper organisational background, we would have had no authorisation and no human or financial resources whatsoever at our disposal to promote the cause of e-learning at the University. During the present research, it was therefore imperative that we pay special attention not only to the numerical components [2] like the results of the load testing, but also to the organisational and community factors.

By establishing the TTDLC, the leadership of the university intended to methodologically update and streamline the education at the CUB and to provide sufficient technological support to this end. The leadership vision and the dedication came from the Vice-Rector of Educational Affairs, while the Chancellery provided the resources necessary to perform the task at hand extensively in a professional way. The fact that our enterprise enjoyed the support of the leadership of the ISC that has been cooperating with eLTSC for years was a very important factor and the information technology background provided by ISC also proved to be highly useful.

The contribution of major stakeholders, such as professionally concerned Institutes and Faculties, was also a key element in the foundation of TTDLC. It was, beyond doubt, the Corvinus Business School that played a key role in the process. The teachers and students of this faculty were the most enthusiastic users of the earlier Moodle system and this School was the parent organisation of eLTSC both financially and organisationally.

That the present Moodle of the CUB has become a modern, $21^{\text {st }}$ century LMS both in its design and functionality is the result of the cooperation between the above mentioned organisational units. Obviously, we still have a lot to do in order to fine-tune the system loadability or the everyday application of the modern e-learning functionalities, but generally speaking, the system, as it is, provides an adequate and promising basis for future developments.

The decisions of the above parties and other stakeholders played a crucial role in the development process. According to Huber, we have examined the interest and role of the stakeholders introduced above and summarised the result in the diagram below. [16] 


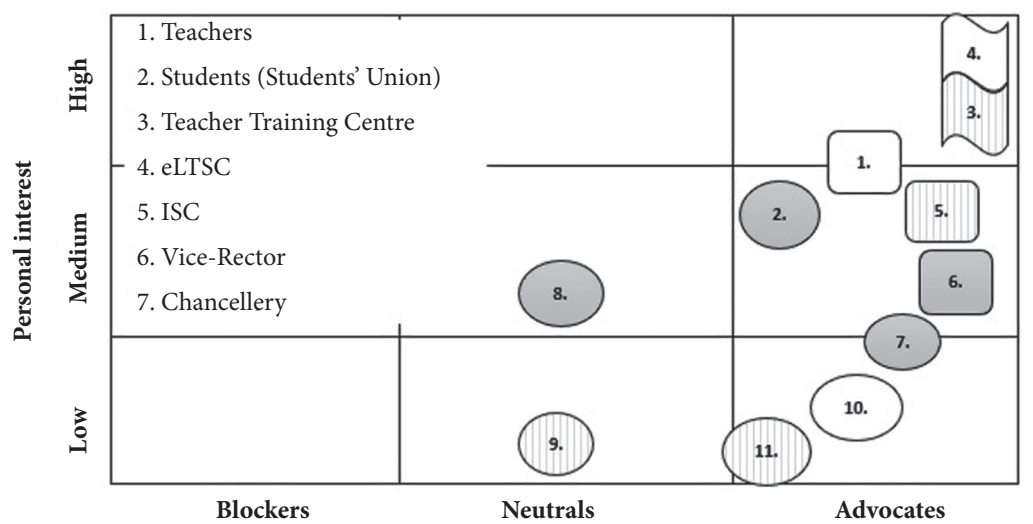

Figure 1. Analysis of key stakeholders in the foundation of TTDLC based on Huber, 2011. [16]

The figure classifies stakeholders based on four dimensions:

1. Personal interest, that can be low, medium or high.

2. Based on their level of support, stakeholders can be blockers, neutrals or advocates of the cause.

3. How much the stakeholder is impacted by the change, which can be low, medium or high.

4. The stakeholder's influence over the organisation which can be low, medium or high.

The diagram shows a number of possibilities that may be grounds for positive outcome. It is noteworthy that no stakeholder displayed blocking behaviour in connection with the foundation of the TTDLC; on the contrary, almost all stakeholders were supportive and advocated the establishment of the organisation. We would like to highlight that even though the interest of stakeholders with the highest influence was not outstanding, the value was around medium. It is rather fortunate that the new approach juxtaposing methodological and technological aspects was the brainchild of two organisations that were not antagonists; quite the opposite was true, as the Teacher Training Centre and the eLTSC were eager to work together and viewed the tasks as exciting challenges and promising opportunities. Another important aspect was that the users, teachers and students alike, supported and welcomed the new organisational unit, they forged positive cooperation with the body and recognised that the process of developing, redesigning and updating the system requires an adequate and supportive organisational structure.

Thus, the new unit could start developing Moodle with proper organisational authorisation and sufficient resources. In the following sections, we will introduce an almost one year long information technology and methodological development.

\section{Specifying the Development Directions}

The base system of the CUB was launched in 2009 by the eLTSC founded within the department on servers provided by the ISC. The first version was the 1.9 release, 
a far more rudimentary system than today's Moodle. After the first major development phase, from 2012, the system relied on the releases above the major version number 2. The development and versioning scheme of Moodle fundamentally changed in 2013, when the developers of the base system switched to the May-November major release pattern, which has been used to date. The next milestone of CUB system development was the switch to version number 3 ; this process was implemented during the development phase analysed in the present article.

In the period between 2012 and 2016 the Moodle base system improved significantly, and the university system also underwent major changes. While in the fall term of the academic year 2012-2013 CUB Moodle had 3,000-5,000 daily visitors, in the fall term of the year 2015-2016 5,000-7,000 people visited the site on a daily basis.

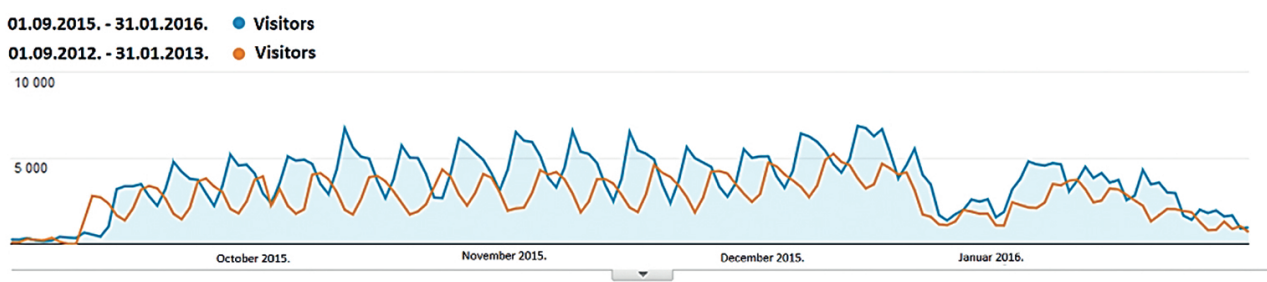

Figure 2. Number of visitors of the CUB Moodle in the fall terms of academic years 2012-2013 and 2015-2016. [Prepared by the authors, 2018.]

Apart from the increase in the number of visitors, the number of sessions grew even more significantly (by 48\%) and the number of views rose dramatically (by 118\%). This meant that an increasing number of students were using the platform more and more actively, performing activities in a continuously growing number of courses. To further illustrate this statement, we compared the number of published courses in the two terms ${ }^{4}(115 \%$ increase) and the number of files uploaded into the system (156\% increase).

Table 1. Comparison table of the fall terms of 2012-2013 and 2015-2016.

[Prepared by the authors, 2018.]

\begin{tabular}{|c|c|c|c|}
\hline Aspect & $\begin{array}{c}\text { Fall term } \\
2012-2013^{5}\end{array}$ & $\begin{array}{c}\text { Fall term } \\
2015-2016^{6}\end{array}$ & Growth \\
\hline Number of visitors & 81,465 & 95,121 & $+16.76 \%$ \\
\hline Number of sessions & 627,020 & 926,312 & $+47.73 \%$ \\
\hline Number of page views & $3,587,951$ & $7,835,321$ & $+118.38 \%$ \\
\hline Number of revealed courses & 768 & 1,653 & $+115 \%$ \\
\hline Number of uploaded files & 24,315 & 62,325 & $+156 \%$ \\
\hline
\end{tabular}

As the number of university students approached 10,000, in 2016 we took into consideration the previous growth rate when optimising the system for a student population of at least

\footnotetext{
4 Only relevant for the faculties on the Buda campus.

01.09.2012 - 31.01.2013.

01.09.2015 - 31.01.2016.
} 
this value. We also determined increase rates based on previous values. When summarising the results, we will also review whether our forecast on the planned growth rate was accurate.

The increased load illustrated above prompted that the task of the new organisational unit was, first of all, to update the system. Our primary considerations were not functionality or design-related; we understood that first we had to address the issue of stability.

\section{Developing a Complex System Which Is Stable, Has a Wide Variety of Functions and Looks Great on any Device-Results}

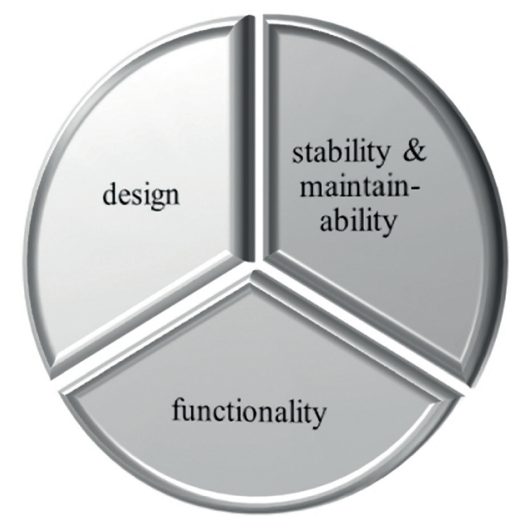

Figure 3. Aspects of development. [Prepared by the authors, 2018.]

We proposed to develop the system along three aspects: stability and long-term maintainability (1), functionality (2) and design (3). The order also signifies the priority we attached to the certain aspects. Regarding functionality, our point of departure was the user and operator needs we had been collecting for years. Most of these needs were met "automatically" when the updated system version was launched; major developments, however, were carried out while we updated the examination module. Many developments aimed to provide support for administration, such as the administrator views in connection with leaders' reporting and the beginning of the terms.

From a design point of view, it was obvious that members of the new generations $\mathrm{Y}$ and $\mathrm{Z}$ could only crack a somewhat condescending smile at the former Moodle design, while responsiveness, a basic expectation brought about by the proliferation of mobile phones was also highly accentuated. Once the Moodle version was updated, we called in graphic designers and managed to come up with a generally accepted design, which, on the one hand, met the various expectations of the CUB, while, on the other hand, represented a neat interface allowing great user experience.

In connection with the design, we created a brief, anonymous survey of 5 questions in 2017 after the system went live. Nearly 900 respondents took part in the survey and we found that the new design appealed to the public. As shown in Figure 4, most respondents 
gave ratings of at least 4, but more often 5 to the questions, which means that they were satisfied or very satisfied with the new system, as compared with the old one.

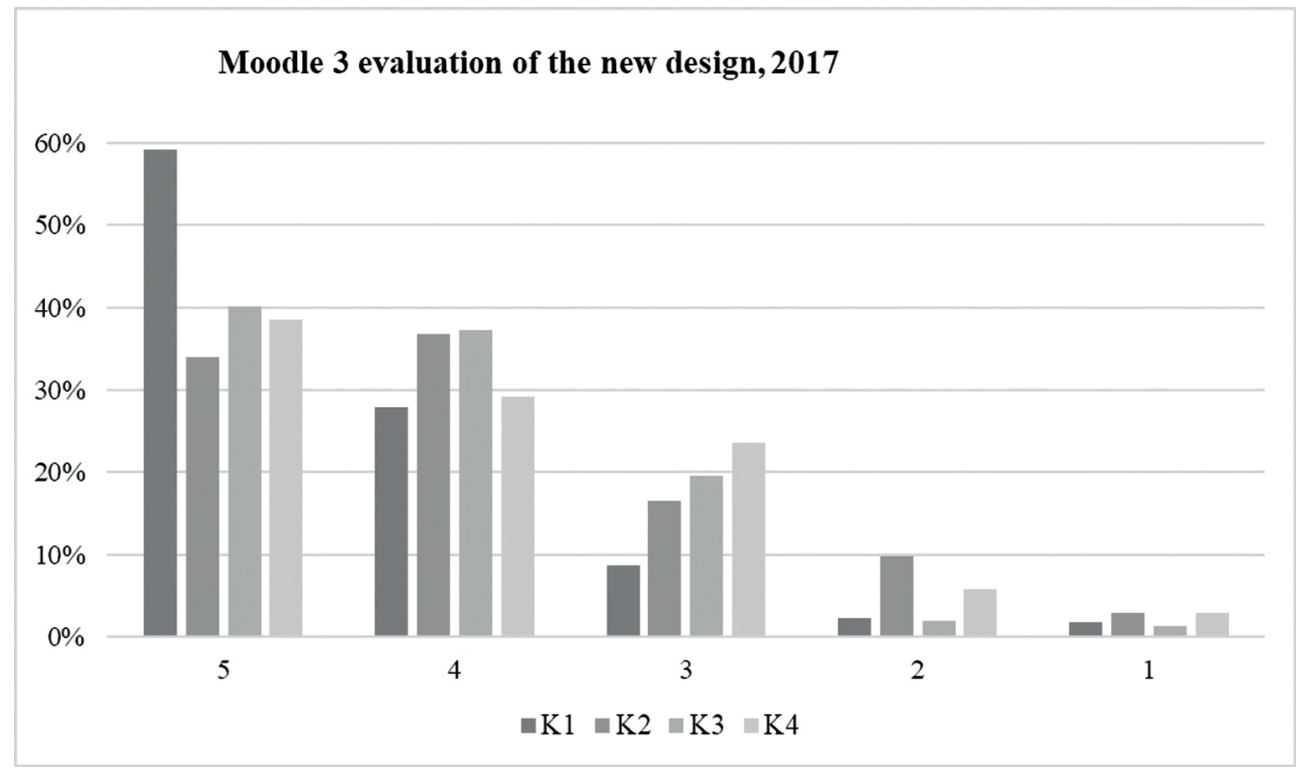

Figure 4. The findings of the 2017 survey on the new Moodle design. [Prepared by the authors, 2018.]

$\mathrm{K} 1$ asked users to rate the system from an aesthetic point of view, while K2 focused on the neatness and ease of use. From both aspects, positive answers greatly outnumbered the neutral or negative ratings (scores 4 and 5 made up $87 \%$ and $71 \%$ of the answers, respectively). Many ratings 3 were given for K3 that measured the playfulness of the system and for K4 that asked respondents about how the system looks on their smartphone displays. This score meant that according to many respondents, the new system in these respects were similar to the old version of Moodle. However, for both questions we received a very high number of positive scores (77\% and 67\%, respectively). In light of the above findings, we evaluated the new design as a success, but, in order to get a full picture, we conducted another survey in May 2018. This time, we asked respondents to rate the new system only, so they were not required to compare it with the old version.

475 respondents returned the 2018 survey and they generally gave positive feedback on the system design. The figure below shows that in all respects, the new Moodle received ratings of 3 and 4 . This time the respondents had no neutral option, therefore a rating of 1 meant the most negative feedback, 2 meant a slight dissatisfaction, 3 signified a slightly positive feedback, while 4 meant a very positive, highly satisfied attitude. 


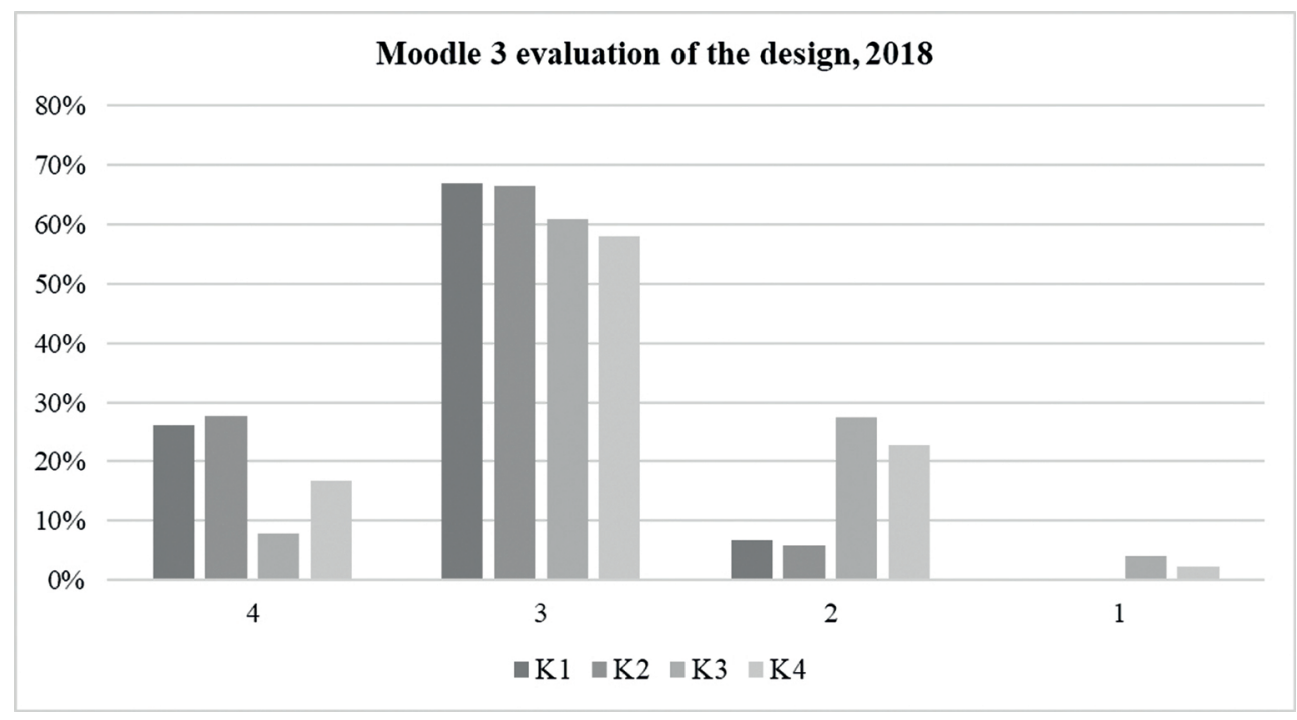

Figure 5. Findings of the 2018 survey on the new Moodle design. [Prepared by the authors, 2018.]

Similarly to the previous survey, K1 referred to the aesthetic aspect and K2 measured the ease of use. The number of negative ratings was very low for both questions, but almost one third of the users expressly liked the design. The number of outstandingly positive ratings (4) for K3 (trendiness) and K4 (appearance on mobile devices) dropped to 8\% and $17 \%$ respectively, and the negative feedback (2) rose dramatically, to $27 \%$ and $23 \%$, respectively. All in all, positive ratings ( 3 and 4) outnumbered the negative answers (69\% and $75 \%$, respectively), while the number of ratings signifying utter refusal (1) remained insignificant for these questions, too.

The above results considering user opinion on the system design matched our expectations. The new system represented a serious improvement compared to the old one, but our findings were not without certain caveats: with the advance of technology, Z-generation users expect a university system not only to be robust and stable but also to look trendy and appealing, therefore, the design is not to be neglected in the future, either.

Being pressed for space, we shall focus on the stability and maintainability of the system in the present article, since we believe that these two factors are the cornerstone of any other development process.

Establishing a stable and maintainable system necessitated developments on two fields:

1. The first problem was posed by the continuously and significantly growing storage needs: due to the increase in user number and activity, the storage capacity of the system servers had to be enhanced continuously. These ever-growing needs brought about financial challenges and the procurement processes often could not be completed in due time.

2. Outstanding load on the database during examinations caused the system to slow down or crash, therefore performance and usability often fell below acceptable levels. We 
addressed this issue by implementing a number of administrative and technical tools; however, we have yet to find a comprehensive solution to fully eliminate the problem.

We set out in multiple directions to find solutions for both issues. As for the storage space, we understood that in the absence of a competent organisational background and decision-making process, all content previously stored in the system was available for both the professors and the students of the CUB. While it was a convenient solution for the teachers, it made the system nearly unmaintainable. The establishment of the TTDLC created the organisational framework necessary for making the appropriate methodological and information technology decisions toward the development of the system. For both the bachelor's and the master's training programs, we agreed to store courses, files and all other content through all faculties of the university for a period of four terms. Since educational institutions are legally obliged to store certain information, files and data (e.g. exam results, homework assignments) for a longer period, we needed to develop an archiving solution rather than a delete mechanism. The main task of the archiving module is to free storage space. The developed module, that is currently being tested, automatically archives the content stored in the system five terms prior to the beginning of a new term. The developed public platform of the CUB allows access to all the data and information uploaded in the four preceding terms. The archiving module uses the built-in 'save course' function, which saves all documents, activities, logs and user achievements belonging to a course in a separate file. Archived sources are stored by ISC in an assigned archived zone in a retraceable and catalogued format.

As for the examinations, we faced much more complex developmental and organisational challenges. We broke down the development process into several phases, the first of which was completed during the 2016 developments. As the system had to service several students at the same time, first we had to be aware how many examinations or tests or other testing methods are provided by the teachers and what workload demand the parallel processes place on the system. We had no relevant, exact measurement data, therefore, in the first phase we focused on workload analysis, adopting two approaches. One of these was based on the teachers' compulsory self-report, and developments commenced on an examination scheduler module that complemented Moodle's own test module. All teachers of CUB were requested to give the expected number of examinees in a certain period (the system allows a time window for a specific exam to be open for days or even weeks). The system displays the current, expected (estimated) server load at the time of the examination calculated on the basis of the number of participants set for the other tests or examinations. The load is displayed on a colour scale in intervals, and the system offers other timeframes for the examination in an interval of plus or minus 3 days from the currently set date, in all time slots, showing the calculated load for all the slots. This way, the teacher can easily select an alternative time window for the examination.

The second approach involved the analytic measurement of the system workload via so-called stress-testing, when we programmed and ran automated load tests. During the tests, the program applies virtual users to simulate the behaviour of real users; for example, they navigate the site, fill out tests, download files, etc. Testing was performed with the involvement of internal and external experts and was supported by the application JMeter. 
The analyses took place in phases. This article presents the results of the 2017 measurement examining the outcome of the first development phase and lists the achievements of the second phase of the development of the examination module. The results of the extensive testing following the first development phase were presented in the thesis of Imre Szekér. [17]

The objective of the measurement was to determine the maximum number of users the system can provide a stable service for. Stability was investigated from two aspects: one was the crash of the system which can be measured through the appearance of bad packages; the other aspect was the page load time. According to the measurement methodology, testing started with 100 virtual users which was increased by 50 and, toward the end of the testing by 25 at a time. The figure below clearly illustrates the limits of the system loadability.

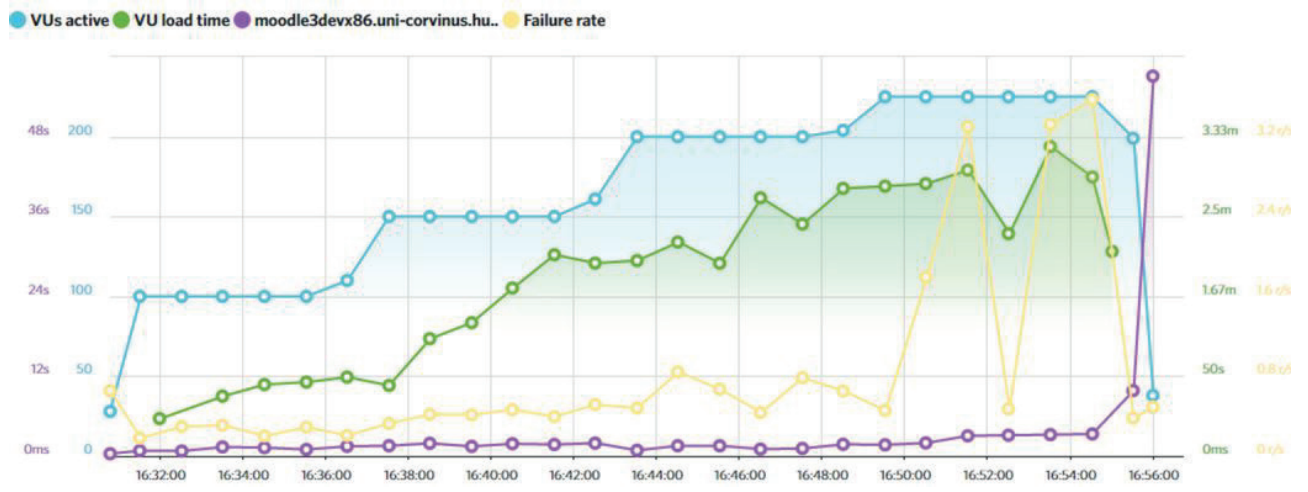

Figure 6. Stress test results. [17]

Virtual users (VU) are marked by the uppermost line, the bottom line (with a spike at the end) represents response time and the (lightest) second line from the bottom marks the margin of error. As the graph shows, at 225 virtual users the margin of error changed dramatically which marks the limits of the stable operation of the system. This means that following the first phase of the development, 200 students could safely take exams at the same time. This result was verified later in the examination period after the system went live. [17]

Following the second phase of the development, we once again scrutinised system loadability with 1,000 virtual users in a number of scenarios. During the test phase our primary focus was on response time. We concluded that if 300 to 510 examinees used the system at the same time, it did not corrupt stable operation. We observed a couple of deviations with a response time of over 10 seconds, but the mean value remained around 1.5 seconds. Test results showed that besides 510 examinees, the system can safely service another 200 users who are performing file operations, for example downloading data.

\section{Conclusions for Theory and Practice}

Subjective user feedback and objective measurement results evidenced that, through our developments, we have managed to create a system that is stable and maintainable in 
the medium term (3-5 years), progressive in its functionality and has a widely accepted design. The above developments and further server configuration allowed doubling the previous number of concurrent examinees (100 students) in the first phase, making it possible for 200 students to take exams simultaneously. Based on the measurements shown above, it is to be expected that the system going live in the summer of 2018 will once again more than double this number. The system then will be able to service 500 concurrent examinees. This number was the final objective we considered during the developments and it clearly proves that the system operates in a stable and maintainable manner.

In a meta-analysis about IT adaptation, researchers find that the most significant factor is organisational readiness. [18] In our study we have analysed a successful development process. Bálint Blaskovics identified the five most often referenced critical success factors (CSF):

1. the support of the leadership;

2. clearly identified objectives;

3. detailed and up-to-date plan (3);

4. good project-related communication;

5. users also participate in the process and they "to a great extent (or, from the project's point of view, to the greatest extent, in extreme cases even in $100 \%$ ) contribute to the success of the project”. [19]

Nearly all factors in the above list are true to our development project, too, and they proved to be really important. The organisational readiness was a key starting point in this case, as well. When creating the organisational background, the development received considerable support from the leadership of the CUB (Vice-Rector and Chancellor) (1). The problems to be tackled were identified and the development proposal was defined by TTDLC in a strategic document and also in the institutional development plan of CUB (2). Accordingly, we had detailed and up-to-date plans that facilitated the development process (3), and the communication of the project elements in agreement with all stakeholders (4). Still, what we find most precious was the involvement of users: as Moodle is a grassroots initiative, it has always been our priority to take into consideration the opinion of the teachers and students, i.e. that end-users of the system (5). As for our recommendations, we consider the CSF list above as our point of departure, as our analysis confirmed that these "most referenced" factors are relevant to the development of an e-learning system for tertiary education, as well.

Our first recommendation for the development of a stable and maintainable system servicing an entire university is that all stakeholders are to define and specify common goals, ensuring the consistency of the development process. Any institution of tertiary education includes several faculties, institutes and service units, making the list of stakeholders very long. We have found that it is recommended for any organisation undertaking a system development to secure the continuous involvement of the following stakeholders, if applicable: chancellery, the leader responsible for educational affairs, IT service provider, library, representatives of the faculties, dedicated "champions" of the already existing LMS (typically certain teachers, administration officials, representatives of institutes) and students' union. The second most important factor is to win the support of the leadership. Their dedication is necessary for any team to carry out the necessary developments. As 
far as our experience goes, until a similar project enjoys no high-level support, it is not worth making arrangements towards any system development. We also recommend setting up a dedicated organisation unit responsible for planning the development, for the future operation of the system and for the communication that is of highest importance. We have also observed that the existing educational system is not capable of changing overnight. As far as e-learning is concerned, one may often experience institutional resistance to change and the application of old rather than innovative solutions, therefore, it often requires considerable effort to make stakeholders understand the importance of such developments.

Nevertheless, a couple of limitations needs to be addressed. With the above introduced systematic research aspect, we included a higher education organisation case study into this paper, therefore, a comparative analysis would show more relevant information. Also, the frame of the current article does not allow for an in-depth analysis of the CFSs, such an analysis may be specified as the subject for further research.

\section{References}

[1] NAGYNÉ TAKÁCS V. - KOVÁCS L.: Az információbiztonsági vezetői szakirányú továbbképzés tapasztalatai. [Partial Experience of Specific Training for Leaders of Information Security.] Pro Publico Bono, 4 (2015), 85-99.

[2] BALKÁNYI P. - ORBÁN Zs.: Aktor alapú társadalom-technológia kapcsolat vizsgálata az e-learning világában. [Studying the Relation of the Actor-based Technology and Society in the World of e-learning.] Gazdaság és Társadalom [Economy and Society], 1-2 (2012), 271-287.

[3] KOVÁCS L. - NEMESLAKI A. - ORBÓK Á. - SZABÓ A.: Structuration Theory and Strategic Alignment in Information Security Management: Introduction of a Comprehensive Research Approach and Program. AARMS, 161 (2017), 5-16.

[4] BIELLI P. - NEMESLAKI A.: Reinventing organizations with information and communication technologies. In. The Future International Manager. London, Palgrave Macmillan, 2009. 94-115. DOI: https://doi.org/10.1057/9780230274068_6

[5] HAMEED, M. A. - COUNSELL, S. - SWIFT, S.: A conceptual model for the process of IT innovation adoption in organizations. Journal of Engineering and Technology Management, 293 (2012), 358-390. DOI: https://doi.org/10.1016/j.jengtecman.2012.03.007

[6] CSILLAG S.: A kooperatív akciókutatás elmélete és gyakorlata. [The Theory and Practice of the Cooperative Action Research.] Prosperitas, 32 (2016), 36-62.

[7] BENBASAT, I. - GOLDSTEIN, D. K. - MEAD, M.: The Case Research Strategy in Studies of Information Systems. MIS Quarterly, 11369 (1987), 369-386. DOI: https://doi. org/10.2307/248684

[8] YIN, R. K.: Case Study Research: Design and Methods. Thousand Oaks, Sage Publications, 1984.

[9] ZOLNAI E.: Kvalitatav módszerek alkalmazási lehetőségei a szakdolgozat megírása során. [Possibilities of Applying Qualitative Methods in Thesis Writing.] In.

R. FEDOR A. - HUSZTI É. szerk.: Kutatásmódszertani kézikönyv. [Research Methodology Handbook.] Debrecen, Debreceni Egyetemi Kiadó, 2016. 
P. BALKÁNYI, Zs. ORBÁN: Institutional Adoption of a Learning Management System...

[10] FLYVBJERG, B.: Five Misunderstandings About Case-Study Research. Qualitative Inquiry, 122 (2006), 219-245. DOI: https://doi.org/10.1177/1077800405284363

[11] STAKE, R. E.: The Art of Case Study Research. Thousand Oaks, Sage Publications, 1995.

[12] YAZAN, B.: Three Approaches to Case Study Methods in Education: Yin, Merriam, and Stake. The Qualitative Report, 202 (2015), 134-135.

[13] BABBIE E.: A társadalomtudományi kutatás gyakorlata. [The Practice of Social Science Research.] Budapest, Balassi Kiadó, 2008.

[14] NAGY V.: E-learning ABC. Vezetéstudomány [Budapest Management Review], 4712 (2016), 6-15. DOI: https://doi.org/10.14267/VEZTUD.2016.12.0

[15] BALKÁNYI P. - ORBÁN Zs.: Virtuális információk a fizikai térben: a kiterjesztett valóság jövőképe. [Virtual Information in the Physical Space: The Future Vision of Augmented Reality.] Információs Társadalom [Information Technology], 1 (2011), 64-80.

[16] HUBER T.: Projekttervezés és projektmenedzsment. [Project Planning and Project Management.] Budapest, ELTE TTK, 2011.

[17] SZEKÉR I.: E-learning rendszer teljesítmény tesztelése. [Performance Test of an e-learning System.] Budapest, Corvinus Egyetem, 2017.

[18] HAMEED, M. A. - COUNSELL, S. - SWIFT, S.: A meta-analysis of relationships between organizational characteristics and IT innovation adoption in organizations. Information and Management, 495 (2012), 218-232. DOI: https://doi.org/10.1016/j.im.2012.05.002

[19] BLASKOVICS B.: Impact of Leadership Styles on Project Success. The Case of a Multinational Company. Dynamic Relationships Management Journal, 3 (2014), 21-36.

[20] TTDLC's tasks and activities. http://eloszk.uni-corvinus.hu/index.php?id=50118 (Downloaded: 10.09.2018) 